\title{
Ethanolic Extract of Garcinia mangostana L. pericarp as Preservative in Antacid Suspension
}

\author{
Richelle Ann M. Manalo, ${ }^{1}$ Erna C. Arollado, ${ }^{1,2}$ Irizh-Lyn R. Sampang, ${ }^{1}$ \\ Janvin Jessel A. Cariscal ${ }^{1}$ and Gerwin Louis T. Dela Torre ${ }^{1}$ \\ ${ }^{1}$ Institute of Pharmaceutical Sciences, National Institutes of Health, University of the Philippines Manila, \\ ${ }^{2}$ Department of Pharmacy, College of Pharmacy, University of the Philippines Manila
}

\begin{abstract}
Objective. The study was conducted to determine the preservative activity of ethanolic extract of mangosteen (Garcinia mangostana L.) pericarp and its compatibility in an antacid suspension.

Methods. The extract was subjected to phytochemical screening and was used as preservative in a formulated antacid suspension. Compatibility with the active pharmaceutical ingredient (API) and excipients were analyzed using fourier transform-infrared spectroscopy. Preservative activity of the formulation against Escherichia coli, Staphylococcus aureus, and Pseudomonas aeruginosa was assessed using the United States Pharmacopoeia (USP) antimicrobial effectiveness test, with methylparaben as positive control and suspension without preservative as negative control.
\end{abstract}

Results. The extract exhibited pharmaceutical compatibility with API and excipients. The formulation revealed comparable reduction in microbial count of E. coli, S. aureus, and P. aeruginosa with positive control at Day 14 $(p=0.916,0.624,0.335)$. At Day 28 , comparable activity with positive control was only observed against $E$. coli and S. aureus $(p=0.999,0.854)$. However, it displayed significant increase in activity against $P$. aeruginosa $(p=0.010)$ at Day 28. These activities may be attributed to glycosides and reducing substances present in the extract.

Conclusion. The ethanolic extract from Garcinia mangostana L. pericarp acted as a preservative in the formulation of an antacid suspension. It conformed to the USP criteria for antimicrobial effectiveness test on bacteria.

Key Words: antimicrobial test, Garcinia mangostana, preservative, suspension

\section{INTRODUCTION}

Foodborne diseases and microbial spoilage are persistent concerns in both developing and developed countries, mainly driven by advances in production techniques, climate change, and widespread trade of food and drug products. ${ }^{1}$ To mitigate these concerns, preservatives are added to prevent decomposition or any undesirable effects in the finished products. ${ }^{2,3}$ The United States Pharmacopoeia (USP) and National Formulary (NF) define preservatives as substances added to non-sterile dosage forms to protect them from microbial growth or from microorganisms that are introduced inadvertently during or subsequent to the

Corresponding author: Richelle Ann M. Manalo Institute of Pharmaceutical Sciences,

Room 212, National Institutes of Health Building, University of the Philippines Manila,

632 Pedro Gil Street, Manila, 1000, Philippines

Telephone: +6325772001

Email: rmmanalo4@up.edu.ph manufacturing process. ${ }^{4}$ They act as antimicrobial chemicals in cosmetics, pharmaceuticals, foods, and industrial products to protect the consumer against infections and the product itself against microbial spoilage. ${ }^{5,6}$ Synthetic preservatives are commonly used for these purposes, however, they are highly discouraged due to their ill effects in humans, ${ }^{7,8}$ 
such as their carcinogenic risks. ${ }^{9}$ Thus, there is a need to search for alternative preservatives that are effective and safer, such as natural preservatives from plants, to control biodeterioration and biodegradation in food, cosmetics and pharmaceutical products.

Plants have been widely used for treating and preventing diseases. They contain a wide variety of secondary metabolites with high structural diversity correlated with their function. Different studies revealed that extracts from plants have the ability to inhibit the growth of microorganisms. Therefore, plant extracts can be utilized for the discovery of new bioactive compounds that could be used in the development of food, cosmetic and pharmaceutical preservatives, in place of synthetic ones.

The Philippines has numerous plants which can be used as potential sources of preservatives. One of the plants known to possess pharmacological activities is mangosteen (Garcinia mangostana L.). Various researches revealed the antimicrobial activity of $G$. mangostana fruit extracts in different microorganisms. ${ }^{10-12}$ However, the use of these extracts as preservatives has not been studied. Thus, this study aimed to investigate the ethanolic extract of $G$. mangostana pericarp (EEGMP) as a potential preservative in pharmaceutical liquid preparation, specifically in antacid suspension.

\section{MATERIALS AND METHODS}

\section{Plant collection and preparation of extract}

Mature mangosteen fruits, with purple-colored pericarp, were bought from Paco Public Market, Manila, Philippines. A specimen was submitted to the National Museum of the Philippines-Botany Division and was identified as Garcinia mangostana L. (voucher number: 170-2014). The extraction of the sample was based on the method of Arollado et al with minor modifications. ${ }^{13}$ The samples were washed thoroughly and the pericarps were obtained, cut into small pieces, airdried and milled into powder. The powdered sample was macerated in $95 \%$ ethanol for 72 hours, with intermittent shaking. The extract was then filtered and concentrated using rotary evaporator (MRC ROVA-2L). The concentrated extract was evaporated to dryness to obtain the EEGMP. It was stored in an amber bottle container at $4^{\circ} \mathrm{C}$.

\section{Phytochemical screening}

The EEGMP was tested for the presence of tannins, glycosides, reducing substances, plant acids, saponins, and flavonoids as described in the methods of Camposano et al. ${ }^{14}$ The results were recorded as $(+)$ for the presence and $(-)$ for the absence of the specific secondary metabolite. The $\mathrm{pH}$ of the extract was also determined using a $\mathrm{pH}$ meter (Trans BP3001).

\section{Preparation of antacid suspension}

Oral antacid suspension, with aluminum hydroxide as active pharmaceutical ingredient (API) and EEGMP as preservative, was prepared using the formulation described in Table $1{ }^{15}$ Positive control suspension was also prepared with methylparaben as preservative, while negative control suspension was prepared without any preservative. Good compounding practices (i.e., use of sterile glassware and clean work area) were observed to limit the suspension's microbial load.

\section{Compatibility studies}

The interaction of the API and each excipient with EEGMP was determined using fourier transform infrared (FTIR) spectroscopy. ${ }^{16}$ The FTIR spectra of each excipient, API, EEGMP, and their mixtures were determined using Thermo Nicolet 6700 FTIR spectrometer in the range of $4000-500 \mathrm{~cm}^{-1}$. Each excipient or API and EEGMP was mixed in a 1:1 weight ratio and kept in refrigeration for seven days. The powdered samples were then analyzed by potassium bromide $(\mathrm{KBr})$ pellet method while liquid samples were evaluated as films placed on $\mathrm{KBr}$ plates.

\section{Antimicrobial effectiveness test}

The antimicrobial effectiveness test for bacteria described in the USP ${ }^{4}$ was used to determine the preservative activity of the EEGMP on isolated cultures of Escherichia coli (ATCC 25922), Staphylococcus aureus (ATCC 25923) and Pseudomonas aeruginosa (ATCC 27853). The test organisms were bought from the Department of Medical Microbiology of the College of Public Health, University of the Philippines Manila. The microorganisms were diluted in buffered sodium chloride-peptone solution $\mathrm{pH} 7.0$ and turbidities were compared to $0.5 \mathrm{McF}$ arland standard equivalent to a

Table 1. Formulation of oral antacid suspension

\begin{tabular}{lcl}
\multicolumn{1}{c}{ Component } & Composition (\%w/v) & \multicolumn{1}{c}{ Use } \\
Aluminum hydroxide & 6 & Active pharmaceutical ingredient (API) \\
Sorbitol solution & 40 & Stabilizing agent, humectant \\
Syrup & 10 & Filler/Flavor enhancer \\
Glycerine & 20 & Co-solvent, viscosity enhancer \\
Xanthan gum & 0.5 & Suspending/gelling agent \\
Methylparaben or EEGMP or none & 0.2 & Antimicrobial preservative \\
Strawberry flavor & 4 & Flavoring agent \\
Purified water & qs & Diluent \\
\hline
\end{tabular}

qs - quantum sufficiat; EEGMP - ethanolic extract of Garcinia mangostana pericarp 
count of $1 \times 10^{8}$ colony-forming units (cfu) $/ \mathrm{mL}$. A $0.1-\mathrm{mL}$ aliquot of each standardized inoculum was transferred to the formulated suspensions and mixed thoroughly. The resulting solutions were incubated at $22.5 \pm 2.5^{\circ} \mathrm{C}$. A $0.1-\mathrm{mL}$ aliquot of each solution was sampled at Days 0,14 and 28, spread over the surface of the soybean-casein digest agar medium, and incubated at $32.5 \pm 2.5^{\circ} \mathrm{C}$. The number of cfu present in each solution was determined and the change in $\log _{10}$ values of the concentration in $\mathrm{cfu} / \mathrm{mL}$ was computed at the applicable sampling intervals. These changes were expressed in terms of log reductions. Suspensions without preservative and with methylparaben as preservative were also prepared, and served as negative and positive controls, respectively. An effective preservative should have no bacterial increase from the initial calculated count at Days 14 and 28, based on USP criteria for product category 4 (antacids made with an aqueous base).

\section{Statistical analyses}

The data gathered were recorded as mean (standard error of mean, SE), with all measurements done in triplicate. The computed log reduction values were used to determine the statistical differences among the formulated suspension, positive control, and negative control using one-way analysis of variance (ANOVA) followed by Tukey's post hoc test

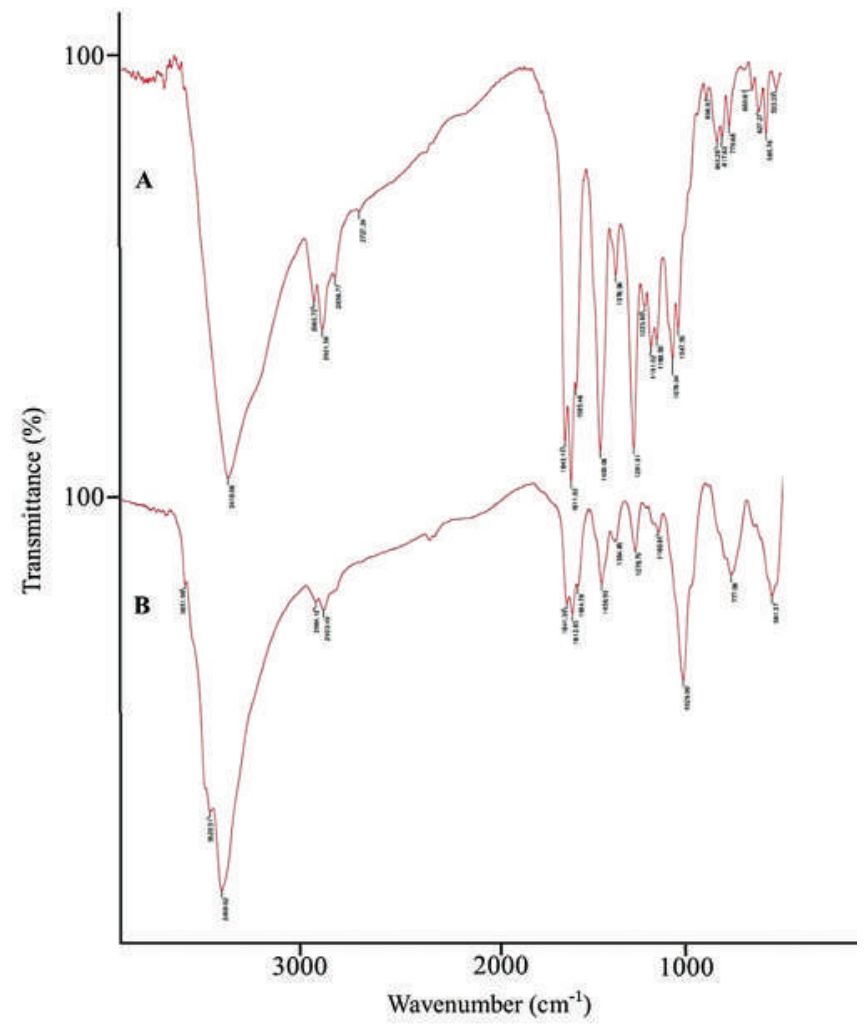

Figure 1. IR spectra of (A) ethanolic extract of $G$. mangostana pericarp and (B) mixture of ethanolic extract of $G$. mangostana pericarp and aluminum hydroxide. of SPSS 23.0 software. Probability values, $p<0.05$, were considered statistically significant.

\section{RESULTS AND DISCUSSION}

Preservatives are either natural or man-made compounds added to foods, medicines and other products, to prevent degradation from microorganisms and oxidative products. These compounds protect the consumers against food-borne illnesses and sensitivity reactions that may result from such degradation. In this study, an antacid suspension was formulated using EEGMP as preservative. The compatibility of EEGMP with the API and excipients were explored, as well as its preservative activity against $E$. coli, $S$. aureus, and P. aeruginosa.

Compatibility study was done to determine the interaction of EEGMP with the API or excipients used in the formulation. The FTIR spectra of the components of the formulated antacid suspension and their mixtures were analyzed for their characteristic absorption bands. EEGMP

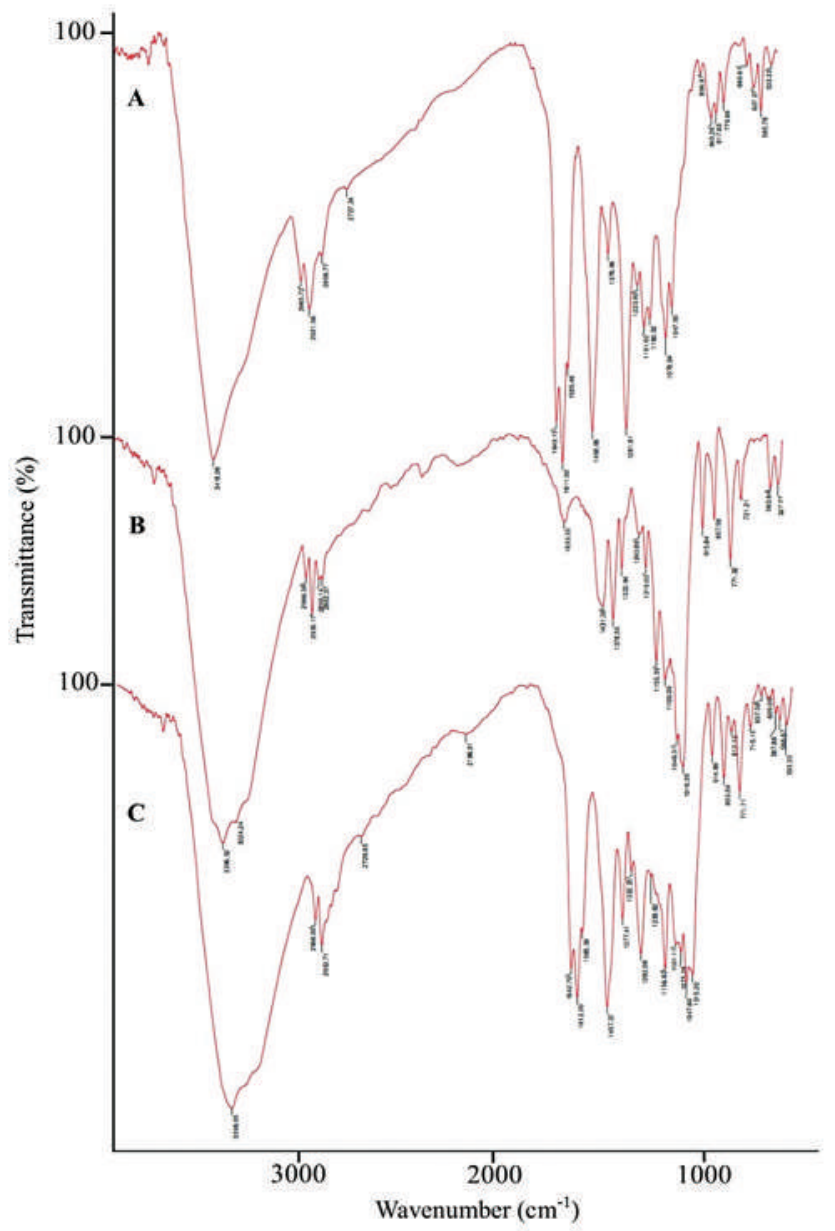

Figure 2. IR spectra of $(A)$ ethanolic extract of $G$. mangostana pericarp, (B) glucose and (C) mixture of ethanolic extract of G. mangostana pericarp and glucose. 
showed characteristic bands at $3418 \mathrm{~cm}^{-1}$ (O-H stretch), 2921 $\mathrm{cm}^{-1}$ (C-H stretch), $1643-1458 \mathrm{~cm}^{-1}$ (aromatic $\mathrm{C}=\mathrm{C}$ stretch), $1281 \mathrm{~cm}^{-1}\left(\mathrm{C}-\mathrm{O}\right.$ stretch) and $1078-585 \mathrm{~cm}^{-1}$ (aromatic C-H bend) (Figure 1A). This was found to be in agreement with the reported spectrum of anthocyanins, occurring mainly as glycosides of anthocyanidins, found in the G. mangostana pericarp. ${ }^{17}$ The spectrum EEGMP-aluminum hydroxide mixture (Figure 1B) revealed the presence of signature peaks of EEGMP at $3651-3458,2964-2923,1641-1458,1278$ and $1029-561 \mathrm{~cm}^{-1}$.

The FTIR spectrum of syrup displayed distinct absorption bands at 3396 and $3324 \mathrm{~cm}^{-1}(\mathrm{O}-\mathrm{H}$ stretch), $2966-2882 \mathrm{~cm}^{-1}$ (C-H stretch), $1633 \mathrm{~cm}^{-1}\left(\mathrm{H}_{2} \mathrm{O}\right.$ vibrational bend), $1431-1333 \mathrm{~cm}^{-1}$ (O-H bend), $1210 \mathrm{~cm}^{-1}$ (C-H bend), $1155 \mathrm{~cm}^{-1}$ (C-C bend in plane), $1109-1016 \mathrm{~cm}^{-1}$ $\left(\mathrm{C}-\mathrm{O}-\mathrm{C}\right.$ bend) and $915-721 \mathrm{~cm}^{-1}$ (absorption for $\alpha-\mathrm{D}-$ glucopyranoside), which was congruent with the reported fingerprint regions of glucose. ${ }^{18,19}$ The characteristic peaks of EEGMP at around $1642-1457$ and $1282 \mathrm{~cm}^{-1}$ (Figure 2A) and glucose at around 3398, $2966-2932,1377,1156$,

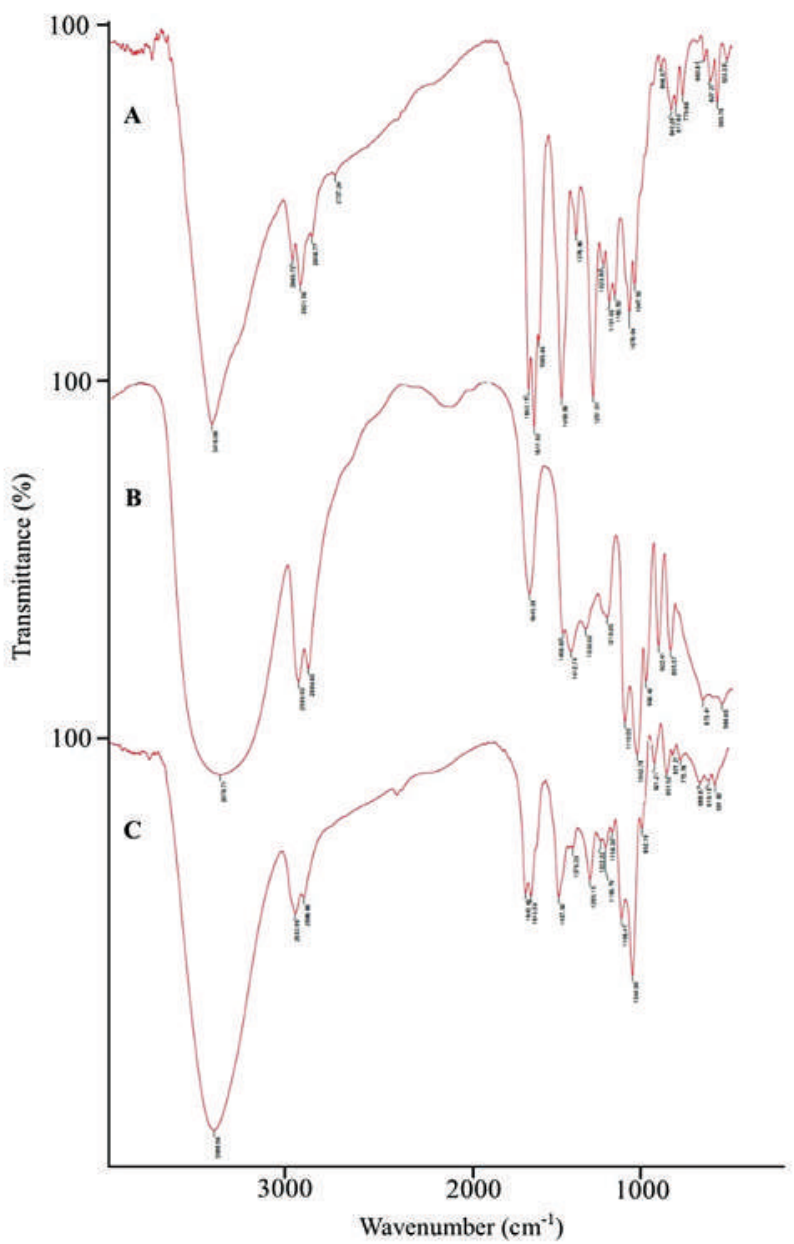

Figure 3. IR spectra of (A) ethanolic extract of G. mangostana pericarp, (B) glycerine and (C) mixture of ethanolic extract of $G$. mangostana pericarp and glycerine.
1015 and $914-715 \mathrm{~cm}^{-1}$ (Figure 2B) were observed for the mixture of EEGMP and glucose (Figure 2C).

The FTIR spectrum of the glycerine sample revealed similar peaks at $3378 \mathrm{~cm}^{-1}$ (O-H stretch), 2939 and 2864 $\mathrm{cm}^{-1}$ (C-H stretch), $1456-1412 \mathrm{~cm}^{-1}$ (O-H bend) and 1110 $-1042 \mathrm{~cm}^{-1}$ (C-O stretch) described in the study of Indran et al. ${ }^{20}$ The respective signature peaks of EEGMP at around $1643-1457,1283$ and $992-581 \mathrm{~cm}^{-1}$ (Figure 3A), and peaks at around 3388, $2933-2886,1106-1044 \mathrm{~cm}^{-1}$ of glycerine (Figure $3 \mathrm{~B}$ ) were present in the EEGMP-glycerine mixture (Figure 3C).

Strong absorption bands at $3394 \mathrm{~cm}^{-1}(\mathrm{O}-\mathrm{H}$ stretch), $2982-2875 \mathrm{~cm}^{-1}$ (C-H stretch), $1471-1253 \mathrm{~cm}^{-1}$ (C-H bend) and $1093-1002 \mathrm{~cm}^{-1}$ (C-O stretch) appeared in the FTIR spectra of the sorbitol sample, which were in agreement with the reported data. ${ }^{21}$ The main peaks of EEGMP at around $1642,1615,1455$ and $1284 \mathrm{~cm}^{-1}$ (Figure 4A) and sorbitol at around 3393, 2932, 1081 and $1047 \mathrm{~cm}^{-1}$ (Figure 4B) were found in the IR spectra of the EEGMP-sorbitol mixture (Figure 4C).

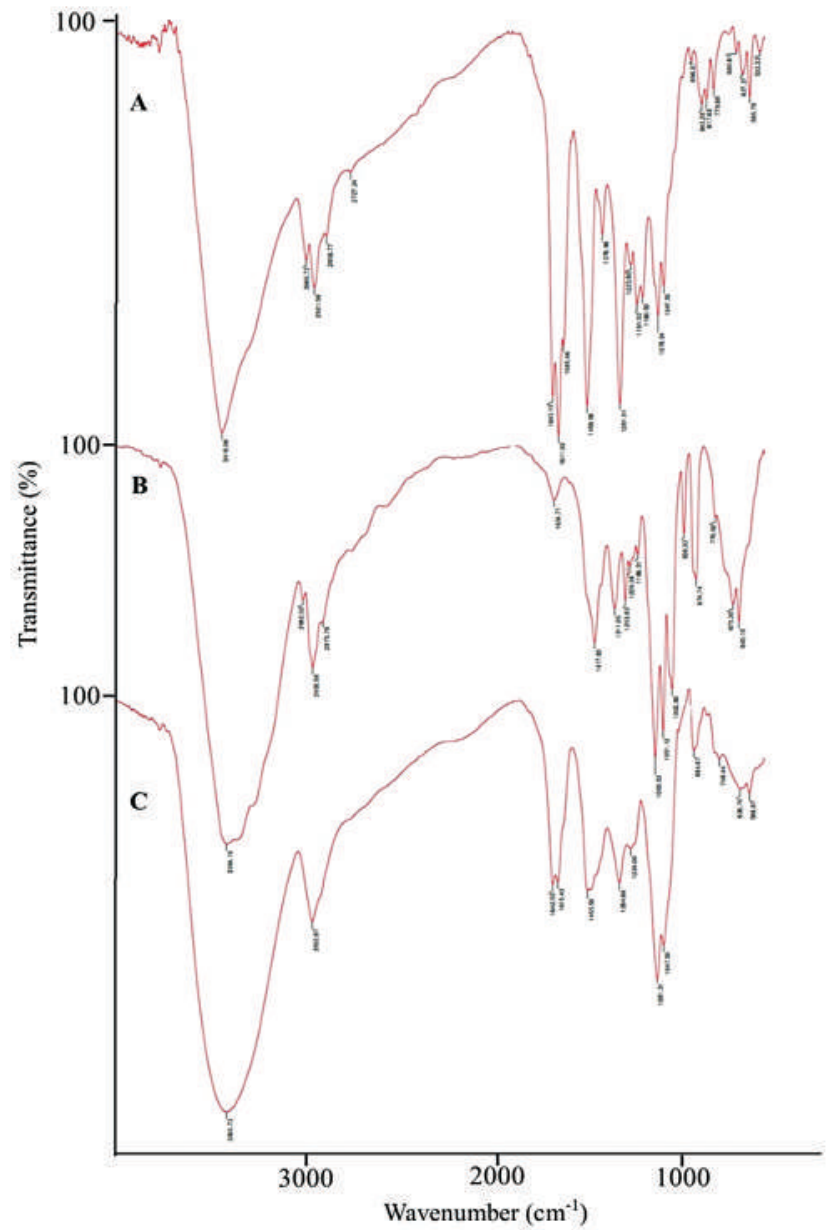

Figure 4. IR spectra of (A) ethanolic extract of $G$. mangostana pericarp, (B) sorbitol and (C) mixture of ethanolic extract of G. mangostana pericarp and sorbitol. 
In the case of xanthan gum, the FTIR spectrum exhibited sharp peaks at $3424 \mathrm{~cm}^{-1}$ (O-H stretch), $2923 \mathrm{~cm}^{-1}$ (C-H stretch), $1726 \mathrm{~cm}^{-1}(\mathrm{C}=\mathrm{O}$ stretch of esters, acids, aldehydes and ketones), $1620 \mathrm{~cm}^{-1}(\mathrm{C}=\mathrm{O}$ stretch of enols), $1455-1380$ $\mathrm{cm}^{-1}\left(\mathrm{C}-\mathrm{H}\right.$ bend) and $1091 \mathrm{~cm}^{-1}$ (C-O stretch), analogous to the spectrum of xanthan gum in previous literature. ${ }^{22}$ Evaluation of the spectrum of EEGMP (Figure 5A) and xanthan gum (Figure 5B) revealed their characteristic peaks at 3418, 2920, $1643-1586,1458,1281$ and $1078-1047 \mathrm{~cm}^{-1}$ in the EEGMP-xanthan gum mixture (Figure 5C).

For commercial strawberry flavor, the IR spectrum showed characteristic absorption bands at $3380 \mathrm{~cm}^{-1}(\mathrm{O}-\mathrm{H}$ stretch due to hydrogen bonding), $2973-2880 \mathrm{~cm}^{-1}$ (C-H stretch), $1647 \mathrm{~cm}^{-1}$ (bending vibration of $\left.\mathrm{H}_{2} \mathrm{O}\right), 1137 \mathrm{~cm}^{-1}$ (C-C bend in plane), which accounted for the propylene glycol and $\mathrm{H}_{2} \mathrm{O}$ present in the strawberry flavor. ${ }^{23}$ The important peaks of EEGMP at around 3415, 1643 - 1458, 1283 and $1078-587 \mathrm{~cm}^{-1}$ (Figure 6A) and strawberry flavor at around $2969-2872$ and $1133 \mathrm{~cm}^{-1}$ (Figure 6B) were well-preserved in the spectra of EEGMP-strawberry flavor (Figure 6C).

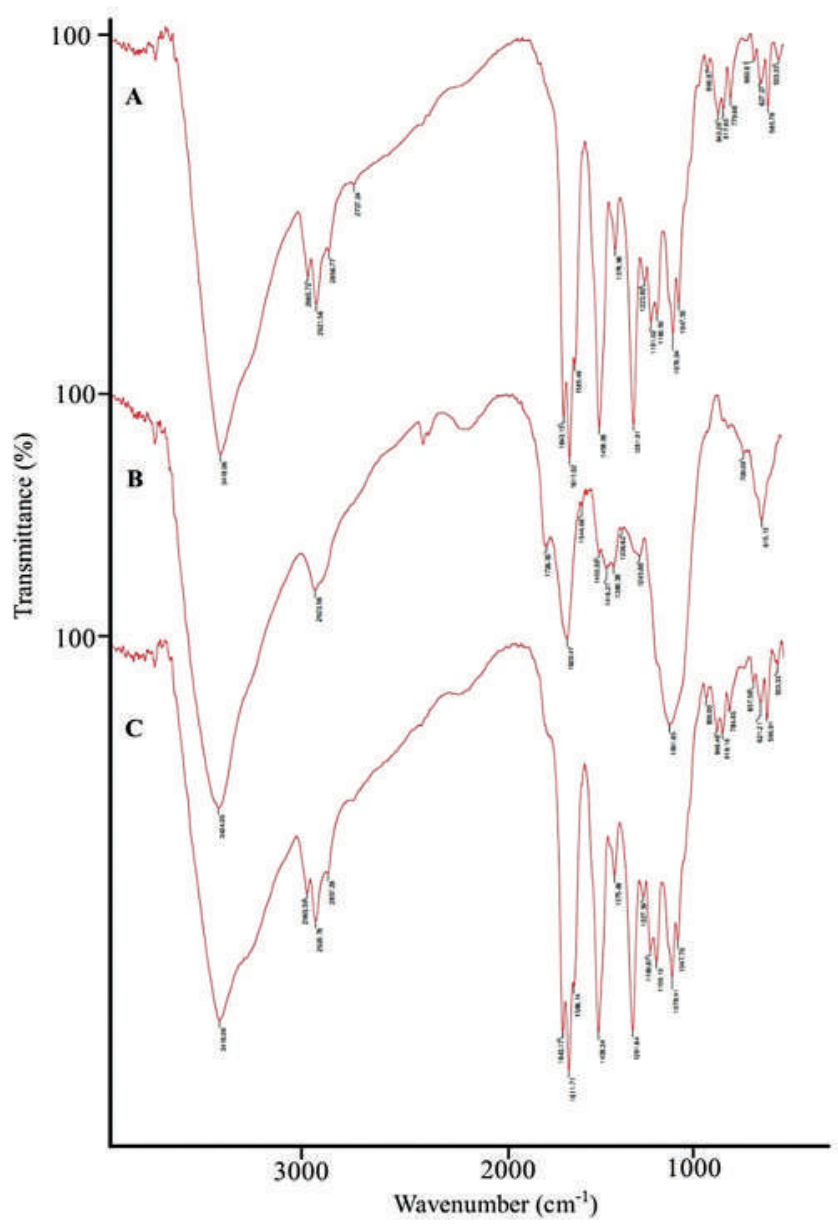

Figure 5. IR spectra of (A) ethanolic extract of G. mangostana pericarp, (B) xanthan gum and (C) mixture of ethanolic extract of $G$. mangostana pericarp and xanthan gum.
Overall assessment of the FTIR analyses indicated that no pharmaceutical incompatibilities occurred in the mixtures of EEGMP with the API or excipients used in the formulation.

To evaluate the EEGMP's preservative activity in the formulated antacid suspension, antimicrobial effectiveness test was conducted. The formulated antacid suspension using EEGMP as preservative showed reduction in the microbial count of E. coli, $S$. aureus, and P. aeruginosa (Table 2) from the initial count to 28 days.

Comparable log reduction values were observed in the EEGMP suspension and positive control against $E$. coli at Day $14(p=0.916)$ and Day $28(p=0.999)$. Comparison of negative control with EEGMP suspension and positive control revealed statistically different $\log$ reduction values at Day 14 ( $p=0.043$ and 0.018 , respectively) and Day 28 ( $p=0.040$ and 0.046 , respectively). Log reduction values of EEGMP suspension against $S$. aureus were also comparable to that of positive control at Day $14(p=0.628)$ and 28 $(p=0.854)$. At Day 28, the negative control displayed no

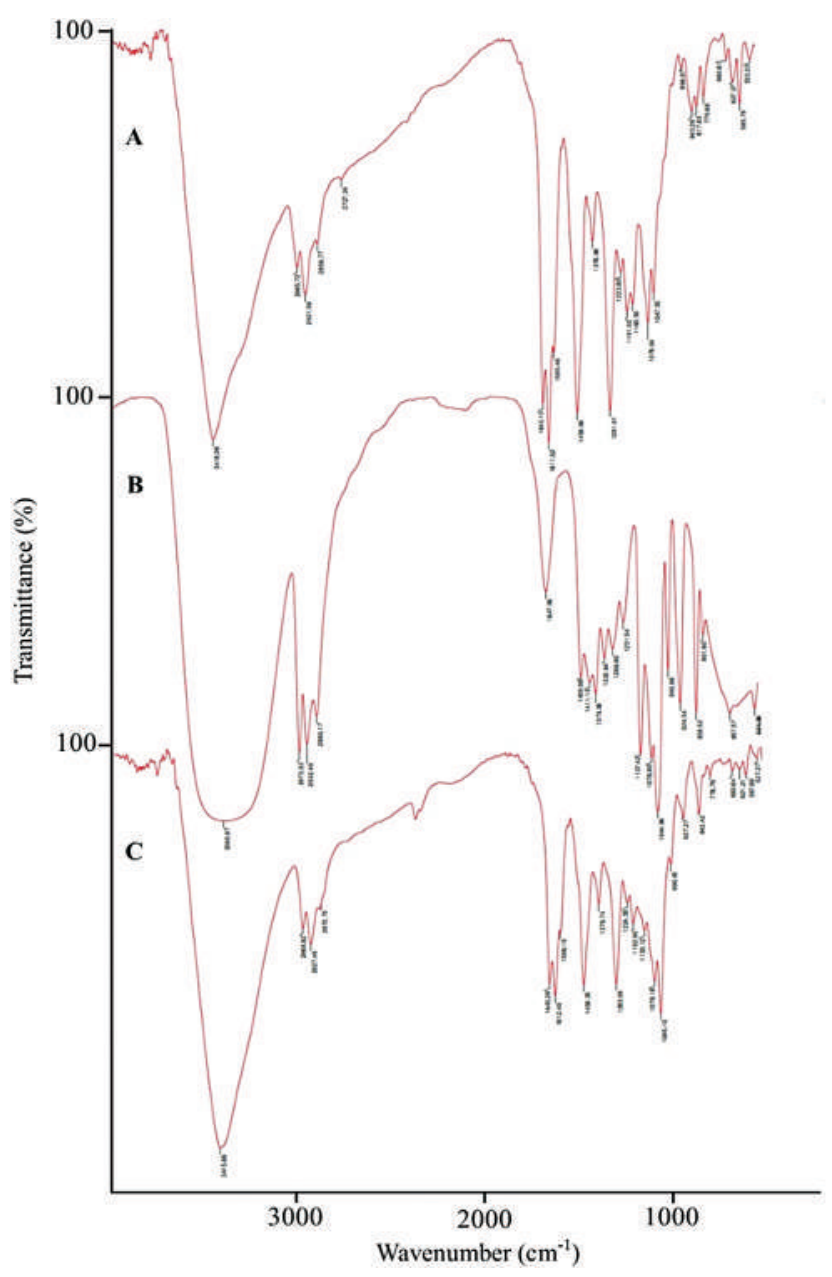

Figure 6. IR spectra of (A) ethanolic extract of G. mangostana pericarp, (B) strawberry flavor and (C) mixture of ethanolic extract of $G$. mangostana pericarp and strawberry flavor. 
Table 2. Antimicrobial effectiveness test of the formulated antacid suspension with ethanolic extract of Garcinia mangostana pericarp (EEGMP) or methylparaben as preservative against Escherichia coli, Staphylococcus aureus and Pseudomonas aeruginosa

\begin{tabular}{lcccc}
\multicolumn{1}{c}{ Sample Formulation } & \multicolumn{3}{c}{ Microbial count x 104, cfu/mL } & \multicolumn{2}{c}{ Log reduction, log cfu/mL } \\
Day 14 & Day 28
\end{tabular}

Methylparaben was used as standard preservative (positive control) while suspension without preservative served as negative control. The values were reported as mean (SE) of triplicate measurements. Significant difference of the formulation $(p<0.05)$ with the positive control was marked with ${ }^{a}$ while negative control was marked with ${ }^{b}$.

Table 3. Phytochemical screening of ethanolic extract of Garcinia mangostana pericarp (EEGMP)

\begin{tabular}{lc} 
Test & EEGMP \\
$\mathrm{pH}$ & 4 \\
Tannins & $(-)$ \\
Glycosides & $(+)$ \\
Reducing substances & $(+)$ \\
Plant acids & $(-)$ \\
Saponins & $(-)$ \\
Flavonoids & $(-)$ \\
\hline
\end{tabular}

Experiment was done in triplicate. Symbols (+) and (-) signify the presence and absence of the secondary metabolite, respectively

significant difference with both EEGMP suspension $(p=0.522)$ and positive control $(p=0.922)$. For $P$. aeruginosa, comparable $\log$ reduction value was demonstrated by EEGMP suspension with positive control $(p=0.142)$ and negative control $(p=0.067)$ at Day 14 . However, at Day 28, EEGMP suspension showed significant increase with positive $(p=0.001)$ and negative controls $(p=0.001)$.

EEGMP conformed to the preservative standards of Category 4 products, which are antacids made with an aqueous base, based on the criteria set by the USP. This activity may be due to the presence of glycosides and reducing substances in the EEGMP (Table 3) as detected in the phytochemical screening. Common anthocyanins found in G. mangostana pericarp are cyanidin-sophoroside, cyanidin-glucoside-pentoside, cyanidin-glucoside, cyanidinglucoside- $X$, cyanidin- $X_{2}$, and cyanidin $X$, where $X$ is an unidentified residue. ${ }^{24}$

Anthocyanidins and cyanidin-3-glucoside have demonstrated potent inhibition in the growth of gram negative bacteria but were not active against gram positive bacteria. ${ }^{25}$ This agrees with the observed higher log reduction values of EEGMP when used as preservative against E. coli and $P$. aeruginosa compared to $S$. aureus. The inhibition of these compounds against microorganisms is said to work by disrupting the bacterial cell membrane. This results in the inactivation of bacterial enzymes and transport proteins by entering the inner membrane. In turn, this inhibits cell respiration and growth, ensuing bacterial cell death. This has been demonstrated in the work of Anandhi et $\mathrm{al}^{26}$ which showed that bacterial cultures treated with glycoside compounds have increased concentrations of reducing sugars and proteins in the medium as a result of leakage caused by cell wall damage.

\section{CONCLUSIONS}

The EEGMP did not exhibit any pharmaceutical incompatibility with the API and excipients used in the formulation, as shown by the results of FTIR analyses. Moreover, the formulated antacid suspension with EEGMP as preservative inhibited the growth of E. coli, S. aureus, and P. aeruginosa up to 28 days, which conformed to the criteria of the USP antimicrobial effectiveness test for antacids made with an aqueous base. The glycosides and reducing substances present in the extract may be the compounds responsible for this bioactivity. Hence, the results of the study can be used as a starting point for the development of other pharmaceutical preparations utilizing EEGMP as preservative.

\section{Acknowledgments}

We would like to acknowledge the financial support given by the National Research Council of the Philippines (NRCP).

\section{Statement of Authorship}

All authors approved the final version submitted.

\section{Author Disclosure}

All authors declared no conflict of interest. 


\section{Funding Source}

This paper was funded by the National Research Council of the Philippines (NRCP).

\section{REFERENCES}

1. Havelaar AH, Brul S, de Jong A, de Jonge R, Zwietering M, ter Kuile B. Future challenges to microbial food safety. Int J Food Microbiol. 2010; 139(S1):S79-S94. doi.org/10.1016/j.ijfoodmicro.2009.10.015.

2. Pawar HA, Shenoy AV, Narawade PD, Soni PY, Shanbhag PP, Rajal VA. Preservatives from nature: a review. Int J Pharm Phytopharmacol Res. 2011; 1(2):78-88.

3. Shalini S. Natural antioxidant - a review. Inter J Phytotherapy. 2012; 2(1):7-15.

4. United States Pharmacopoeia 38 - National Formulary 33. Chapter 51. Antimicrobial Effectiveness. Rockville, Maryland: United States Pharmacopoeial Convention; 2015. pp. 100-3, 2499.

5. Ostrosky EA, Marcondes EMC, Nishikawa SD, et al. Rubus resaefolius extract as a natural preservative candidate in topical formulations. AAPS PharmSciTech. 2011;12(2):732-7. doi: 10.1208/s12249-0119635-9.

6. Sultana T, Rana J, Chakraborty SR, Noor R. Microbiological analysis of common preservatives used in food items and demonstration of their in vitro anti-bacterial activity. Asian Pac J Trop Dis. 2014; 4(6):452-56. doi.org/10.1016/S2222-1808(14)60605-8.

7. Wilson BG, Bahna SL. Adverse reactions to food additives. Ann Allergy Asthma Immunol. 2005; 95(6):452-507. doi.org/10.1016/ S1081-1206(10)61010-1.

8. McCann D, Barrett A, Cooper A. Food additives and hyperactive behavior in 3-year old and 8/9-year-old children in the community: a randomized, double-blinded, placebo-controlled trial. Lancet. 2007; 370(9598):1560-7.

9. Gharavi N, Haggarty S, El-Kadi AO. Chemoprotective and carcinogenic effects of tert-butylhydroquinone and its metabolites. Curr Drug Metab. 2007; 8(1):1-7.

10. Vishnu Priya V, Mallika J, Surapaneni KM, Saraswathi P, Chandra SGVS. Antimicrobial activity of pericarp extract of Garcinia mangostana Linn. Int J Pharma Sci Res. 2010; 1(8):278-81.

11. Gettha RV, Anitha R, Lakshmi T. Evaluation of antibacterial activity of fruit rind extract Garcinia mangostana Linn. on enteric pathogens an in vitro study. Asian J Pharm Clin Res. 2011; 4(S2):115-18.

12. Lim SY, Lee SSH, Tan CB. Antioxidant capacity and antibacterial activity of different parts of mangosteen (Garcinia mangostana Linn.) extract. Fruits. 2013; 68(6):483-9.

13. Arollado EC, Bucog LP, Manalo RAM. Comparative analysis of the antimicrobial and antioxidant properties of selected plant extracts as natural preservatives in ointment formulations. Eur J Pharm Med Res. 2015; 2(4):757-68
14. Camposano JE, Dela Torre GLT, Laxamana JG, Larcia LLH II. Screening for the anti-angiogenic activity of selected Philippine medicinal plants using chorioallantoic membrane assay. Mahidol Univ J Pharm Sci. 2016; 43(4):172-82.

15. Arollado EC, Bucog LP, Manalo RAM, Sampang IR, Cariscal JJA. Selected Philippine plant extracts as preservatives for a pharmaceutical liquid preparation. Phil J Sci. 2017; 146(1):7-13.

16. Pani NR, Nath LK, Acharya S, Bhuniya B. Application of DSC, ICT and FTIR study in the compatibility testing of nateglinide with different pharmaceutical excipients. J Therm Anal Calorim. 2012; 108:219-26.

17. Munawaroh H, Fadillah G, Saputri LNMZ, Hanif QA, Hidayat R, Wahyuningsih $\mathrm{S}$. The co-pigmentation of anthocyanin isolated from mangosteen pericarp (Garcia mangosteen L.) as natural dye for dyesensitized solar cells (DSSC). 10th Joint Conference on Chemistry. IOP Conf Ser: Matter Sci Eng. IOP Publishing [Online]. 2016 [cited 2017 January]. Available from http://iopscience.iop.org/ article/10.1088/1757-899X/107/1/012061/pdf.

18. Adina C, Fetea F, Taoutaou A, Socaciu C. Application of FTIR spectroscopy for a rapid determination of some hydrolytic enzyme activity on sea buckthorn substrate. Rom Biotech Lett. 2010; 15(6):5738-44

19. Srisuthep R, Brockman R, Johnson JA. Infrared and raman spectra of maltooligosaccharides. Cereal Chem. 1976; 53(1):110-17.

20. Indran VP, Zuhaimi NAS, Deraman MA, et al. An accelerated route of glycerol carbonate formation from glycerol using waste boiler ash as catalyst. RSC Adv. 2014; 4:25257-67.

21. Shaikh SF, Mane RS, Min BK, Hwang YJ, Joo O. D-sorbitol-induced phase control of $\mathrm{TiO} 2$ nanoparticles and its application for dyesensitized solar cells. Sci Rep. 2016; 6:20103. doi: 10.1038/srep20103.

22. Faria S, Petkowicz CLDO, de Morais SAL, et al. Characterization of xanthan gum produces from sugar cane broth. Carbohydr Polym. 2011; 86(2):469-79.

23. Crupi V, Majolino D, Migliardo P, Venuti V. Inter- and intramolecular hydrogen bond in liquid polymers: a Fourier transform infrared response. Mol Phys. 2000; 98(19):1589-94. doi. org/10.1080/00268970009483364.

24. Palapol Y, Ketsa S, Stevenson D, Ferguson IB. Colour development and quality of mangosteen (Garcinia mangostana L.) fruit during ripening and harvest. Postharvest Biol Technol. 2009; 51(3):349-53. doi.org/10.1016/j.postharvbio.2008.08.003.

25. Puupponen-Pimia R, Nohnyek L, Meier C, et al. Antimicrobial properties of phenolic compounds from berries. J Appl Microbiol. 2001; 90:494-507. doi.org/10.1046/j.1365-2672.2001.01271.x.

26. Anandhi D, Srinivasan PT, Praveen Kumar G, Jagatheesh S. Influence of flavonoids and glycosides from Caesalpinia coriaria (Jacq) Wild. as bactericidal compound. Int.J.Curr.Microbiol.App.Sci 2014; 3(4): 1043-51. 